\section{Carnaval en \\ Paraguay: los festejos urbanos y el Arete Guasu}

\section{RESUMO}

En el primer parte de esta investigación ${ }^{1}$ se analizan, en términos de procesos comunicacionales, dos maneras de festejar el carnaval en Paraguay: los festejos urbanos y la celebración autóctona con el ritual guaraní del Chaco. Abarca el análisis de los estilos amorfos de las festividades en las principales concentraciones urbanas y cabeceras departamentales del país, en contraste con lo que tiene de religioso y de pagano la celebración en una comunidad de la etnia de los chiriguanos en el Chaco paraguayo, comunidad que es parte de la familia lingüística Tupi-Guaraní.

\section{ABSTRACT}

The first part of this article discusses the two forms of Carnaval celebration in Paraguay, one urban and the other guarany, in the countryside. (The second part will be published on the next issue)

\section{PALAVRAS-CHAVE (KEY WORDS)}

- Carnaval (Carnival)

- Festas populares (Folk celebrations)

- Paraguai (Paraguay)

\section{Vicente Brunetti}

Investigador Internacional em Comunicação e Educação, Especialista em Estratégias e Projetos de Informação Pública e Comunicação Educativa

\section{Primera parte}

Diferencias existentes en las características que poseen las fiestas de carnaval, en el ámbito urbano y en el de una etnia autóctona

Consideramos el festejo del carnaval como un sistema colectivo de comunicación, en el que existen sentidos simbólicos en los mensajes originados, tanto en el estilo de organización, como en el cuerpo, en la vestimenta, en los accesorios, en los ornamentos diversos, en los bailes, en la letra y en la música de las canciones utilizadas.

En anexos se incluye la bibliografía utilizada, así como, entre otras, la ficha técnica de un documento audiovisual preparado por el Departamento de Teleducación del Ministerio de Educación y Cultura, sobre una celebración del Arete Guasu en una comunidad de los chiriguanos, en el Chaco paraguayo.

Analizamos los mensajes diversos en torno a los nudos de sentidos que vinculan la celebración a los elementos de la religiosidad y del paganismo, en los respectivos marcos de interrupción de la vida cotidiana, en los siguientes aspectos:

1.1 Ausencia de religiosidad en las celebraciones de las fiestas urbanas, en contraste con el profundo sentido religioso del Arete Guasu

El clima profano y caótico, de desenfado y desenfreno, propio de la celebración 
urbana del carnaval, y el conjunto de sus características formales y expresivas, están completamente despojados de toda referencia o alusión a la religiosidad, por parte de los participantes en los festejos, en total contraste con el origen de los diversos elementos que son utilizados, en el caso de la celebración indígena del Arete Guasu, en la que se verifican las raíces profundamente religiosas de la fiesta.

En lo que atañe a las características principales de la religión, Bartomeu Meliá definió sintéticamente:

"La religión de los Guaraní actuales, que en su estructura y en su función, perpetúa la religión de los antiguos Guaraní, puede ser definida como inspiración, sacramentalizada en el canto y en la danza, dirigida por mesías en búsqueda de la tierra sin mal". ${ }^{2}$

La sólida creencia en una divinidad suprema, creadora; así como la existencia de dioses mediadores y de héroes civilizadores con funciones semejantes, y la de genios confundidos con los hechos de la naturaleza, expresados en los diversos mitos ancestrales, como el mito del diluvio, el mito de los gemelos, la utopía recurrente de la tierra sin mal, son los grandes rasgos que, con variantes de nombres y de detalles, se repiten a lo largo del área Guaraní-Tupí.

La trascendencia del fenómeno religioso es tal que, como lo señala Bareiro Saguier, constituye la mayor fuente de la vasta y hermosa literatura oral de los Guaraní.

Bareiro Saguier ${ }^{3}$ sintetiza las principales características de la religión guaraní:

1. "Es preciso distinguir entre el concepto estratificado, jerarquizado y dividido que caracteriza a la religión en la sociedad occidental, del fenómeno religioso en la cultura guaraní.
En esta se trata de un sentimiento que impregna tanto los hechos y fenó-menos de la naturaleza, como los actos, aun los más cotidianos, de la vida social. De cada fenómeno y de cada acto pues, emana, en forma natural y espontánea, un aliento que guarda relación y está en correspondencia con una esfera de lo sagrado".

\section{2. [En la religión guaraní]}

"...conviven los dioses y los hombres, como muy bien lo señala Pierre Clastres (ver "Profetas en la jungla").

En la religión guaraní, la máxima aspiración es... alcanzar la condición de la inmortalidad, atributo supremo de los dioses y de sus elegidos. Inmortalidad a la que es posible tener acceso -mediante oraciones, danzas y ayunos- en esta vida, pues la Tierra sin Mal, la de la perfección eterna, se encuentra en algún sitio de esta tierra. En suma, esa convivencia se opera en un grado tal, que implica, como culminación ideal, la equiparación de los hombres a los dioses".

1.2 Sesgo de militarización en las manifestaciones de las fiestas urbanas, en contraste con ancestrales elementos democráticos guaraní

El sesgo de militarización presente en las manifestaciones de las fiestas urbanas, queda demostrado, tanto en la formación jerárquica que respetan los participantes (organizada en filas, escuadras, etc.), como en la adopción de diferentes elementos evocadores del mundo militar y paramilitar, tales como uniformes, gorros, escudos, insignias y diversos distintivos.

Por contraste, las características citadas como indicios de militarización en las fiestas urbanas, no están presentes en la celebración autóctona del Arete Guasu.

Además, recordamos el carácter que 
posee la autoridad circunstancial de la persona que dirige un desfile (denominado figura principal, director, o mariscal de campo) que, en forma autoritaria, dirige los pasos y el desarrollo del festejo en las ciudades; frente al carácter de autoridad representativamente comunitaria del mburuvicha (jefe), entre los guaraní.

De acuerdo a Pierre Clastres, ${ }^{4}$ tres son las propiedades del líder indígena:

1. "El jefe es un "hacedor de paz"; es

la instancia moderadora del grupo".

2. "Debe ser generoso de sus bienes, y está al servicio de sus 'administra dos".

3. "Sólo un buen orador puede acce der al liderazgo".

Un antecedente remoto que explica las diferencias cualitativas en el sistema de relacionamiento comunitario, radica en el antiguo modo de elección del jefe tribal guaraní.

En efecto, el origen etimológico del kûimbaé guaraní, emerge de un modelo de democracia comunitaria, con una limitación temporal específica del poder político.

El kûimbaé era elegido alrededor de la fogata, en un ruedo dentro del cual los que aspiraban a ser electos dirigían un discurso a los presentes, con el fin de persuadirlos de sus cualidades y fines.

Era elegido como jefe, por consenso, aquél que exhibía mejor poder de convencimiento en su oratoria, por lo que lo denominaban "kû-i-mbaé".

En idioma guaraní originario, la expresión "kû-i-mbaé" quiere decir "el dueño de su lengua", equivalencia que fue modificada durante el contacto con la presencia cultural transformadora de los jesuítas, y que hizo posible que hoy día, el vocablo sólo denomine al varón, al señor.

1.3 Elementos de la simbología y orden fascistas en los festejos urbanos, frente al "caos" y apropiación utilitaria indígena, de objetos y símbolos ajenos
Muy vinculado y entremezclado con el punto anterior, el aire caótico, de desenfado y de desenfreno, propio de la celebración urbana del carnaval, muchas veces solapa, o disfraza la presencia de diversos elementos de la simbología y orden fascistas que son utilizados por parte de los participantes en los festejos, bastante alejados del origen de los diversos elementos que son apropiados, en el caso de la celebración indígena del Arete Guasu.

En los diversos festejos urbanos en forma de desfiles, carrozas, corsos, murgas, acompañantes, o en fiestas, aparecen algunas personas tatuadas con la cruz gamada, o portando un cartel con la imagen del águila imperial alemana, o con un cuasi-disfraz alegórico a algunos uniformes y banderas del ejército alemán nazi, o accesorios propios de las "SS", cuya exhibición ocurre en nombre de una identidad, militancia o simpatía por la ideología nazi.

El contraste con la celebración comunitaria indígena del carnaval es más que obvio: en el Arete Guasu se verifica el uso de diversos elementos, algunos autóctonos, y otros completamente ajenos a la simbología nativa, como guantes de motociclista, o zapatillas de tenis, o el uso del pantalón vaquero, o de las blusas brillantes de origen coreano, que imitan la seda, o los anteojos oscuros para el sol.

Pero ninguna de las señales, signos o símbolos utilizados en las ciudades como adhesión a la ideología nazi, aparecen durante los días de festejos del Arete Guasu.

En cuanto a la recurrencia por una simetría rebuscada y obsesiva en la mayoría de los desfiles urbanos, contrasta con el orden de caos organizado predominante en el ritual guaraní, y que evoca a la naturaleza.

No es casual la aparición durante los festejos del carnaval en las ciudades, de una serie de referencias a una geometría forzada en las formaciones, ni las diversas alegorías de la marcialidad del "paso 
de ganso", visibles durante las diversas marchas de bailarines, o en clubes sociales y deportivos, y otras instituciones, que se adhieren a los días de fiestas.

1.4 Estrategias Agonales de comunicación en el carnaval urbano, frente a las estrategias mayoritariamente Sinagonales en el Arete Guasu

Este punto lo clasificamos en dos grupos de estrategias, de acuerdo a las características presentes en la celebración del carnaval urbano y en el Arete Guasu, según el sistema clasificatorio del etólogo alemán Ire-näus Eibl-Eibesfeltd.

\subsubsection{Estrategias Agonales de} comunicación en el carnaval urbano

El vocablo agonal viene del griego agon (competición, beligerancia con el enemigo). En la práctica de sus diversos usos, estas estrategias de beligerancia con aquellos considerados como enemigos, no aparecen en forma pura y específica.

Contrariamente, las encontramos entremezcladas o amalgamadas con otras. Hay casos extremos en los que subordinan -o quedan ellas mismas subordinadasa las técnicas de la propaganda de guerra: la propagación de rumores, la escalada psicológica, el despertar temor o paralización, o infundir grados inferiores de autoestima en el bando contrario, o superiores y triunfalistas, de nacionalismo y exaltación, entre las fuerzas propias.

Las principales son:

Estrategias para intimidación y presunción: Exhibición ostentosa, hasta de poder físico, intelectual o económico, que tienen el objetivo de atemorizar y humillar. En el caso de los festejos barriales del carnaval en las urbes, aparecen en los patios y veredas los "globitos" cargados con agua, al que algunos agregan colorantes, tintes y diversas substancias. $Y$ una variedad de recipientes con agua como "apoyo logístico": baldes y palanganas, llegando hasta el uso de mangueras conectadas al sistema de distribución domiciliaria del agua corriente.

Estrategias de provocación y beligerancia: Arrogancia y adopción de varios niveles de agresividad, por más que las personas no estén participando en los juegos.

Estrategias de ataque y lucha: Competiciones rituales y conatos de agresión que llegan hasta el ataque con daños físicos a personas, autovehículos, y unidades del transporte público, con un saldo lamentable de numerosas personas con contusiones, lesiones y cortes debido a la rotura de los vidrios de las ventanas de los ómnibus del transporte público, etc.

Estos hábitos de agresividad y molestias extremas tanto han desbordado los límites de lo aceptable, que desde unos años atrás, la policía nacional adoptó la decisión de detener y llevar presas, a las personas que agredan a otras en la vía pública. Pero nadie denuncia, porque en Paraguay, la policía se caracteriza por sus vínculos con la delincuencia organizada, la ineptitud, la inacción y la torpeza.

Estrategias de defensa: Manifestación preventiva y agresiva de defensión.

Estrategias de retirada: Abandono del sitio o de la posición, en vez del diálogo y de instancias que permitan el compartir.

El uso de las estrategias agonales revelan el carácter agresivo y la agresividad que se verifica en la mayoría de los entornos ciudadanos, en los diversos niveles de juegos que consisten en ataques recurrentes con agua a las y los ciudadanos, aunque sean simples transeúntes que no participan del juego, propiamente, o como ya mencionamos, a las unidades del transporte público, a las que agreden arrojando los globitos de agua, piedras, palos, etc., con un elevado 
saldo de contusos y lesionados.

Cuando la agresividad se desborda por el consumo indiscriminado de bebidas alcohólicas, ocurren múltiples casos de agresión física, violación a mujeres, hombres, adolescentes, niños y niñas, llegando hasta la muerte de las inocentes víctimas.

Por contraste, durante la celebración del Arete Guasu en las comunidades autóctonas, salvo un ataque simulado hacia las mujeres, que veremos en detalle más adelante, se verifica el uso de estrategias sinagonales de vinculación y comunicación.

\subsubsection{Estrategias Sinagonales de comunicación en el Arete Guasu}

El vocablo sinagonal que reúne las estrategias de vinculación y agrupamiento, es un derivado del verbo synago.

El término es el equivalente en griego a: reunir, juntar, hacer amistad, crear vínculos, reconciliar y ser hospitalario.

Su función es la constitución, el mantenimiento y la reparación de los vínculos sociales, así como de la armonía y de la unidad del grupo.

Las principales estrategias, que figuran en la clasificación realizada por el etólogo alemán Eibl-Eibesfeldt, son:

Estrategias de inicio de contacto amistoso y agrupamiento social

Se incluyen entre ellas:

- Ios rituales de saludo,

- las estrategias de solicitación,

- las estrategias de aproximación hete rosexual (vinculadas a las ceremoni

as del cortejo y la seducción).

- las estrategias de invitación al juego,

- las de reconocimiento e instauración de intereses comunes.

Estrategias de reforzamiento de vínculos
Estas abarcan las siguientes:

- los rituales que atestiguan la unidad, como los rituales de acción conjunta, iguales a los rituales entre madrehijo;

- los rituales de sincronización,

- las manifestaciones de participación y de otros intereses comunes;

- los rituales de lucha en común, por ejemplo, contra enemigos imagina dos;

- el cultivo de valores comunes;

- rituales de asistencia mutua como dar bebida, comida, hospedaje.

Estrategias de mantenimiento de armonía del grupo

Se incluyen entre ellas:

- estrategias para mantener la norma del grupo, como las formas de usos correctivos, las de burla, el procedimiento de "poner en la picota" a alguien, y la agresión normativa,

- estrategias de conciliación, en casos de arbitraje, y de consolación,

- estrategias de asistencia, en los casos de apoyo y ayuda,

- estrategias de restablecimiento de vínculos, en los casos de reconciliación, disculpa, expiación, mediación,

- estrategias que evitan la agresión: amenaza de ruptura, sumisión, etc.

- estrategias conciliadoras,

- estrategias para evitar el desafío, y lograr un aplacamiento: actitudes de disimulo, respeto a la norma de propiedad, ritos de reconocimiento: homenaje, loa y otras formas conciliadoras.

2 Implicaciones comunicacionales de la visión cosmogónica y de la percepción antropocéntrica, según las matrices culturales

Veremos muy brevemente las implicaciones 
comunicacionales subyacentes en la percepción antropocéntrica, propia del ámbito urbano; y en la visión cosmogónica guaraní, mediante una lectura que privilegia las matrices culturales de cada uno de los respectivos entornos.

\subsection{La visión antropocéntrica y el origen de} sus debilidades

Algunos de los aspectos que constituyen el origen de la caracterización histórica del Paraguay, son los extensos períodos de gran inestabilidad política, seguidos de largos inmovilismos; la apertura de las fronteras y las sucesivas e interminables entregas de sus múltiples recursos naturales al capital extranjero, y bajo el dominio, control y usufructo de otros países, junto a una etapa de aislamiento total; así como la emergencia de clases políticas parasitarias que engendraron corrupción e impunidad en los gobernantes $y$ en el conjunto de las fuerzas armadas, y dos cruentas guerras en menos de cien años.

El antecedente inmediato de la situación actual de la comunicación en Paraguay, constituye el sistema de gobierno por casi 35 años del dictador Stroessner.

Con una red de alianzas (económicas, políticas, personales) la mayoría de los propietarios de los medios (radios, canales de TV y prensa escrita), así como muchos de sus personeros, fueron cómplices con el régimen, con muy contadas excepciones.

En ausencia de desastres naturales catastróficos, salvo inundaciones cíclicas de desplazamiento lento, el Paraguay se ve obligado a convivir con los principales desastres culturales evocados.

Pese a esos desastres culturales, y sobre todo, debido a esa presencia ominosa, la comunicación sigue siendo vital en el proceso de desarrollo, no sólo del Paraguay, sino de todos los pueblos, para que las personas sean partícipes del mismo desde sus comienzos, y lograr un proceso autogestionario y participativo, que logre el crecimiento y el desarrollo con solidaridad, entre sus miembros 5 .

En el tramo final de la dictadura se dió paso a una actitud más decidida de reflejar la disconformidad ciudadana, mencionando, todavía tímidamente, los casos que demostraban las irregularidades de la administración gubernamental.

En una carta presentada en 1990 al PIDC de la UNESCO, se lee:

“...el inmediato pasado del Paraguay, quedó marcado por una lucha cotidiana, en la cual la sociedad civil y las organizaciones no gubernamentales enfrentaron el oprobio y el bochorno de un sistema autoritario y dictatorial que desde el gobierno anterior intentó arrasar todo vestigio de dignidad cívica, integridad humana y utilización de recursos en toda la nación..."6.

El documento agrega los siguientes elementos como prediagnóstico de la realidad, señalando las características estructurales que, inclusive hasta hoy día, once años después, describen el estado de situación de la sociedad civil:

Las consecuencias más graves se observan en:

a) la confusión conceptual de la ciudadanía toda, como el resultado de una estructura educativa inadecuada para la consolidación de una sociedad autónoma, por haber fomentado el culto al personalismo, el egoísmo, la docilidad y la obsecuencia;

b) el proceso de aislamiento que operó en tres niveles:

I) entre los individuos;

II) entre los diferentes sectores sociales dentro del país y,

III) entre los individuos y actores sociales, y entre éstos y la comunidad internacional, alterando profundamente los procesos de comunicación;

c) el vacío de saber, de conocimiento y de práctica cultural que en la realidad 
desmanteló los principios de respeto, solidaridad, cooperación y justicia; negando el derecho del ciudadano a un proyecto digno de vida;

d) el estado de agresión que soporta la sociedad y la civilidad, por parte de los medios de propagación masiva, subordinados a la publicidad comercial, que en complicidad con productores y distribuidores internacionales de información, atropellan a la ciudadanía en sus valores, en su identidad, y en sus íntimas creencias.

Después del golpe de estado en febrero de 1989, el gobierno permitió y alentó el culto al fascismo y al nazismo, tal como demuestra el documento audiovisual "Marzo paraguayo" , , en el que se observa, por un lado, la adhesión a un totalitarismo concreto y el culto a la brutalidad demostrada por miembros de la policía nacional usando cascos adornados con símbolos específicos, como la gruz gamada nazi, mientras se encargaba de la represión a la ciudadanía; y por otro, el mantenimiento de la coacción y de la agresión, tan afectos al procedimiento de crueldad totalitaria.

La muy breve descripción, permite comprender las condiciones que han caracterizado los festejos del carnaval en las ciudades: carencia de elementos que equivalgan a una identidad cultural, ostentación burda y hasta ridícula de recursos económicos, mediocridad y pobreza expresivas, signos crecientes de violencia, y del culto a la violencia en el relacionamiento, como pasos nítidos de brutalización en el proceso de fascistización ciudadana.

De este moto, los procesos comunicacionales entre las personas, se han visto perturbados profundamente, y distorsionados, en función a lealtades y compromisos vinculados con la corrupción y la impunidad fijadas en los círculos cercanos al poder gubernamental, incluyendo al Poder Ejecutivo, al Poder Judicial y al Poder Legislativo.
Los procesos inherentes a las contiendas electorales que afectan a la sociedad civil, en su rol de electora, como real cuarto poder en cualquier modelo mínimamente democrático, abrió las puertas a una clase política enferma de poder, intelectualmente miope y mediocre, judicialmente delincuente, y en la práctica, inmersa en un modelo de destrucción de ciudadanía.

Con estas condiciones, fue exacerbada una visión antropocéntrica, en la cual los elementos propios de la comunicación entre las y los humanos, han sido distorsionados y situados en función a la delincuencia, con el fin de lograr rápidamente un enriquecimiento ilícito. Y en relación a la comunicación de las personas con el medio ambiente, deterioró los umbrales mínimos de la percepción medioambiental.

La ineptitud de los sucesivos gobernantes, ha conducido al país a la disolución y pérdida de sus fronteras físicoculturales y económicas, sobre todo a lo largo de la extensa frontera del este y del norte, debido a la contínua penetración de colonos y capitales provenientes del Brasil.

Un sector de la prensa ha denunciado cotidianamente estos hechos que, lo ven y lo sufren todas las personas, salvo las autoridades nacionales, como las Cámaras de Diputados y de Senadores, la Cancillería, el Departamento de Migraciones, la Policía Nacional, los Ministerios del Interior y de Defensa Nacional, las Gobernaciones y las Juntas Departamentales, las Municipalidades y sus Juntas Municipales, que deberían haber promovido acciones de custodia de la soberanía nacional, pero que en su ineptitud y mediocridad, eligen permanecer ajenas a estos problemas de la ciudadanía.

El descreimiento, la pérdida de confianza, y la pésima imagen que tiene la ciudadanía de los parlamentarios (diputados y senadores), los convirtió en las figuras públicas más repudiadas en estos doce años de transición hacia la democracia. $^{8}$ 
Como "botón de muestra" de las numerosas transformaciones perjudiciales que ocurren en la extensa frontera con el Brasil, el Diario Noticias de Asunción publicó ${ }^{9}$ un artículo con el título

"En Salto del Guairá, $90 \%$ de las tierras es de brasileños". En el interior del texto, afirma que "Félix Melgarejo, intendente de Salto del Guairá, la capital - del Departamento- de Canindeyú, confirmó que el $90 \%$ de las tierras de la zona de influencia de esta ciudad pertenece a propietarios brasileños".

\section{El artículo aludido agregó que}

"La invasión cultural de los bra-sileños proviene desde hace décadas y toda la población viene clamando para que se haga algo al respecto... No existe ninguna ley de 'franja de segu-ridad' que evite esta penetración. Hay una ley que establece los requisitos para los brasileños que pretendan acceder a un título de propiedad, por ejemplo, pero ¿quiénes la cumplen?”

El artículo tomado como muestra, describe que

"Salto del Guairá es una ciudad de unos 10 mil habitantes, que vive del comercio 'turístico' de compra de brasileños que cruzan el río Paraná en camiones o barcos, desde y hacia Guaíra, Brasil. La actividad económica más importante, sin embargo, corresponde a la agroexportación (soja), aunque se desconozca el volumen oficial de lo exportado hacia el Brasil".

En la región "Desde Curuguaty, en los municipios de Corpus, Katueté, Puenta Kyjá, La Paloma y Salto del Guairá, los pobladores de origen brasileño llegan al 70\%".
En efecto, en esta región, los hábitos culturales de la población criolla, en general, y los lingüísticos y comunicacionales, en particular, se han visto afectados profundamente. En la realidad, los idiomas español y guaraní han cedido paso al portugués y al "portuñol". ${ }^{10}$

Las principales monedas de cambio utilizadas son el real brasileño y el dólar norteamericano $y$, en tercer lugar, el guaraní paraguayo. Por otro lado, para el depósito de dinero diario, son preferidas las instituciones bancarias y financieras ubicadas en territorio brasileño.

La población sintoniza con preferencia las señales de radioemisoras y de canales de televisión brasileños. El artículo citado del Diario Noticias refiere que

"En la región Este del país, especialmente en los departamentos de Alto Paraná y Canindeyú, existen más de 100 emisoras "piratas" en AM y FM, la mayoría de las cuales se encuentra en manos de inmigrantes brasileños o "brasiguayos".

Por su parte, toda esta situación que presenta el tradicional caso de penetración constante, origina que las fiestas y los diversos festejos populares, demuestren una incorporación creciente de elementos culturales del Brasil.

2.2. La visión cosmogónica y los elementos de la matriz cultural autóctona

Tal como lo describe el compatriota Rubén Bareiro Saguier,"1 "Antes de la llegada de los europeos, los guaraní integraban la gran familia, o la nación conocida con el nombre de Guaraní-Tupí". ${ }^{12}$ En el período pre-colonial, el área de influencia de la familia etno-lingüística Guaraní ocupaba una región mucho más grande que la antigua Provincia Gigante de las Indias, bajando por las costas del océano Atlántico, desde más arriba de la desembocadura del Amazonas, hasta más abajo del estuario 
del Plata, en el límite superior de la Pampa, en territorio actual de Argentina.

El rumbo de la dispersión y ocupación guaraní, se extendió hacia el interior del continente, en particular a lo largo de los ríos, alcanzando a lindar al norte y al oeste, hacia los contrafuertes andinos, con el perímetro externo del imperio incaico en las primeras estribaciones del Altiplano, y al este, llegando hasta los territorios habitados por la familia etno-lingüística Tupí, que hoy corresponden al actual territorio del Brasil.

La familia etno-lingüística GuaraníTupí habitaba entonces los que hoy son los territorios de Argentina, Bolivia, Brasil, Ecuador, Guayana, Paraguay, Perú y Uruguay.

El núcleo guaraní, propiamente dicho, estaba centrado entre los cauces de los ríos Paraná y Paraguay, ocupando la actual región oriental del Paraguay, el estado de Mato Grosso y parte de la costa atlántica, en el Brasil, y la provincia de Misiones en Argentina, con algunas grupos en Bolivia por el noroeste, y Uruguay por el sureste.

Según Meliá, ${ }^{13}$ hay sociedades guaraníes, y partes de ellas, en Argentina, Bolivia, Brasil y Paraguay, cuyas culturas se reproducen históricamente en sus acciones.

Y lo que reproducen es la voluntad de un modo de ser que se expresa en un sistema simbólico, sobre todo relacionado por una lengua -el guaraní-, manteniendo una economía de reciprocidad y configurada como una sociedad sin Estado.

Para determinar el concepto de "familia o nación", además de la conocida hipótesis de Métraux sobre los orígenes Guaraní-Tupí se aducen ciertos rasgos comunes principales: la lengua, la estructura social, los elementos de la cultura material y el conjunto de las creencias religiosas.

En Anexos está la Tabla que detalla las cinco familias etnolingüísticas con las 17 etnias correspondientes, y un trabajo sobre la Matriz de Comunicación Oral. ${ }^{14}$
2.3. Acerca del nivel de la percepción equitativa de género

En las ciudades, el montaje de números alegóricos, en el carnaval, está basado, generalmente, en la utilización de determinados estereotipos y prejuicios negativos que dificultan y entorpecen una adecuada percepción equitativa de género.

Los estereotipos y prejuicios surgen del uso de la distorsión referencial, propensa a fijar la discriminación: racial, religiosa, de género y política, como modos que disfrazan el sentido de la realidad y la significación de los hechos y de las cosas.

Aparecen estereotipos sobre minorías sexuales (travestis, homosexuales y lesbianas), mezcladas con otras minorías (étnicas y religiosas), junto a otros actores sociales, como banqueros tramposos, ejecutivos inescrupulosos, políticos corruptos, policías y militares delincuentes, pero presentados de un modo muy grotesco, a modo de un subterfugio que termina acomodándolos como en un juego invisible para seguir imperando en la realidad del día siguiente en el paisaje urbano.

Por su parte, el concepto de sexualidad entre los indígenas no posee el carácter discriminatorio existente en las ciudades, y no se manifiesta en forma grotesca.

En la cultura guaraní, ocurre una identificación específica de roles de acuerdo a criterios de división del trabajo comunitario. La identificación está basada en la distribución de roles y tareas consideradas apropiadas, unas para mujeres, como las tareas de recolección, o las de la cestería, vestimenta, cocción de alimentos, etc.; y otras para hombres, como la recolección, pesca, caza, y construcción de pequeñas embarcaciones, en el interior de estas sociedades de recolectores y cazadores.

En particular, durante la celebración del Arete Guasu, y al mediodía del tercer día, los participantes se semi-entierran con barro simulando ser chanchos, como 
un juego típico de la fiesta, dedicado especialmente a ensuciar a las mujeres, como un símbolo con el que los chiriguanos sienten manifestar un fuerte rechazo a lo ajeno.

Al medio día de la última jornada aparecen los cuchi-cuchi, jóvenes, que según un divertido ritual, se revuelcan en el barro y corren -imitando el andar del chancho-, al sitio en el que la gente danza, como reminiscencia de su paso por tierras andinas.

Cuchi, es una expresión quéchua equivalente a chancho. Como explica el audiovisual de Teleducación, la acción de ensuciar especialmente a las mujeres está probablemente relacionada con un aviso o amenaza a la comunidad, es entonces un típico juego en el que se trata de evitar a todo lo foráneo o extraño a su propia aldea.

Por sobre las críticas que se puedan hacer a una percepción como la descripta, ha permitido que la cultura guaraní disponga, no sólo de una moral, con un comportamiento tolerante hacia la homosexualidad, tanto en los hombres como en las mujeres, sino de una práctica social, capaz de enfrentar de manera más apta los problemas de convivencia, así como disponer de una percepción de género más amplia, tener una sabia competencia en una comunicación más amigable con el medio ambiente, y utilizar una concepción que establece límites al poder político.

Para la mayoría de los miembros de las comunidades indígenas, cuestiones como la nacionalidad de las personas, así como la organización del Estado Nacional, sus instituciones y autoridades, la población criolla en general, y los actores sociales que son ridiculizados en las ciudades, son percibidos como factores que les dejan sin sus tierras y demás recursos de la cultura guaraní, viéndose sojuzgados y explotados con necesidades insatisfechas de trabajo, educación, salud y bienestar comunitario.

2.4 Acerca del nivel de la percepción

\section{medioambiental}

Acerca del nivel de la percepción medioambiental manifestada en los festejos urbanos del carnaval, es poco lo que podemos agregar, salvo que, lo que cada vez es más notorio es, justamente, la inconsciencia de las personas respecto a la dislocación y agresión crecientemente agudizada en contra del medio ambiente.

$Y$ esa actitud central abarca todos los ámbitos de la vida en sociedad: tanto en el interior del hogar familiar, como en la calle y los demás sitios públicos.

En todo caso, en las ciudades y aglomeraciones urbanas en las que las personas practican los juegos con el pretexto de los días de carnaval, impactan desde los desperdicios y basuras dejadas por los participantes en las calles, las plazas públicas y los diversos recintos en general, hasta los productos utilizados indiscriminadamente, sin considerar todavía que posean o no características biodegradables.

En cuanto al nivel de la percepción medioambiental en la cultura guaraní, Alfred Métraux ${ }^{15}$ logró enumerar los numerosos implementos de la cultura material comunes a los componentes de la familia Guaraní-Tupí, lo que demuestra la pertenencia a una misma área cultural, en la cual eran practicados: una agricultura neolítica (rosado), de gran rendimiento, la caza, la pesca, la recolección, la alfarería o cerámica, no sólo para usos funerarios, sino como aplicación para otros utensilios domésticos, así como la cestería, el arte plumario, el tejido y la tintura, entre otros, como rasgos materiales y principales de la misma.

Métraux señala las influencias de otras culturas por razones geográficas, como el caso de la utilización del metal en las comunidades que tomaron contacto con el imperio incaico; en los demás, eran la madera y el hueso, mucho menos frecuentemente la piedra, los materiales primarios utilizados. Métraux dice: 
"Los Tupí-Guaraní aparecen pues como agricultores cuya civilización está perfecta y únicamente adaptada a las condiciones de vida tal cual ella se presenta en las regiones tropicales de la América del Sur. Establecidos generalmente a lo largo de los ríos y de sus afluentes, se han convertido en excelentes navegantes capaces de emprender lejanas expe-diciones..."16

Las características de la vida cotidiana guaraní explica la existencia de una multitud de elementos de enlace y comunicación entre los humanos y la naturaleza, y la construcción de un modelo apto de respeto y convivencia entre las personas, y el cuidado del medio ambiente, reflejado ampliamente en las prácticas celebratorias que todavía sobreviven.

En particular, la celebración del Arete Guasu es la gran fiesta de los chiriguanos, que ofrece cuatro nudos de sentidos: es la gran ceremonia de recuerdo y rememoración, y también de respeto a los antepasados, configura también una ceremonia agrícola propiciatoria, es una instancia de cohesión comunitaria, y es también carnaval.

"Cuando florece el maíz, anuncia el Aticu o Arete Potavo, momento en que se fija la fecha en que, meses después con las espigas ya maduras, se iniciará el Arete Guasu, la fiesta de carnaval en que las almas salen del lugar lejano que habitan para visitar a sus descendientes y ofrecerles la fertilidad de los suelos y la abundancia de los frutos en los cultivos. Es el momento de asegurar que las generaciones se sigan procreando y dar así continuidad a la vida". ${ }^{17}$

De hecho, y como lo explica Escobar, el Arete Guasu es el sistema de máscaras más complejo que existe en Paraguay: “...porque de las distintas máscaras los chiriguanos o mbya o guaraní se identifican, por una parte, con sus antepasados, asumen el rol de sus antepasados muertos, pero también de los animales, mencionan distintos personajes que aparecen, también se convierten en sus propios enemigos, y todo el carnaval chiriguano reproduce la idea del antiguo oguata de los guaraní de un desplazarse continuo y marca el ciclo anual o sea que al cabo de cada carnaval se supone que ellos regresan de una zona mítica que coincide con las siete cabrillas y el flore-cimiento de ciertos vegetales, y en ese momento en que se cruza el tiempo mítico, el tiempo agrícola, el tiempo real es cuando eclosiona la fiesta o sea que los chiriguanos tienen que asumir diferentes roles y esos roles están marcados por las distintas máscaras" . ${ }^{18}$

\section{Notas}

1 Esta investigación contó con la colaboración de Sirley González Ruíz Díaz, quien incansablemente se dedicó durante todo el mes de enero del 2001 a la reunión de datos, clasificación de numerosa documentación, y a diversas transcripciones.

2 Meliá, Bartomeu; De la religión guaraní a la religiosidad paraguaya: una sustitución. En Revista Acción, № 23, Asunción. 1974.

3 Bareiro Saguier, Rubén; Literatura Guaraní del Paraguay. Biblioteca Ayacucho, Caracas. 1980. p. XV.

4 Clastres, Pierre; La Societé contre l'état. Editions de Minuit, París. 1974.

5 Brunetti, Vicente et al., Manual de Comunicación para el Desarrollo. Algunas Técnicas y principios básicos de comunicación alternativa. Trabajar y Compartir-UNESCOUniversidad Católica, Asunción. 1992.

6 Fragmento de una carta dirigida en marzo 5/1990 al 
Dr. Alan Hancock, Director de la División de Libre Flujo de la Información y Desarrollo de la Comunicación, de UNESCO, firmada por el Pbro. Dr. Juan Oscar Usher, Rector de la UNIVERSIDAD CATOLICA, y por Vicente Brunetti, Director de TRABAJAR Y COMPARTIR, a raíz del primer Proyecto paraguayo presentado al PIDC de la UNESCO.

7 "Marzo paraguayo", documento audiovisual que acompaña la primera edición electrónica en INTERNET del libro El Tótem de Rayos Catódicos. Manual de Comunicación para el Perceptor de Televisión. Brunetti, Vicente. Libroline. Alicante, UE. 2001.

8 Durante el largo período de la dictadura de Stroessner, los parlamentarios habían ganado la imagen de haraganes, ignorantes, brutos y torpes, hasta el punto de que, en guaraní, se acuñó la expresión "diputado tavy" que quiere decir "diputado ignorante". Después del golpe de estado de 1989, los parlamentarios de la transición sumaron a su imagen de haraganes, ignorantes, brutos y torpes, los 'atributos' de ambiciosos oportunistas que buscan enriquecerse a cualquier precio, incluyendo las acciones fuera de la ley; inescrupulosos y amorales de tiempo completo, estando muchos de ellos involucrados en numerosos proyectos fascistas; y cada vez más cerca de las macro organizaciones mafiosas y criminales de la región.

9 Las menciones aluden al ejemplar del Diario Noticias de Asunción de fecha julio 29 de 1998, pág. 19.

10 El portuñol es una amalgama lingüística caracterizada por una baja competencia,tanto en el manejo del español, como del portugués, pero que le permite a sus usuarios una comunicación que intenta solucionar la necesidad comunicacional de la vida cotidiana.

11 Bareiro Saguier, Rubén; op. cit.

12 Bareiro Saguier, Rubén; pág. IX, op. cit.

13 Meliá, Bartomeu; 1997; El Paraguay Inventado. CEPAG, Asunción, 1974. pág. 35.

14 La Tabla y el trabajo son de Brunetti, Vicente; El tam-tam de las Tribus Urbanas. Manual de Comunicación para el Oyente de Radio. Facultad Politécnica, UNA-SUIZA. Asunción. 1996.
15 Métraux, Alfred, La civilisation matérielle des tribus TupíGuaraní. Librairie Paul Geuthner, París, 1928.

16 Métraux, Alfred, op. cit.

17 Teleducación, 1997, op. cit.

18 Ticio Escobar, crítico de arte. Entrevistado en Teleducación, 1997. 